\title{
Transarterial embolization of the external carotid artery in the treatment of life- threatening haemorrhage following blunt maxillofacial trauma
}

\author{
Crt Langel ${ }^{1}$, Dimitrij Lovric ${ }^{1}$, Ursa Zabret ${ }^{1}$, Tomislav Mirkovic², Primoz Gradisek², \\ Anita Mrvar-Brecko², Katarina Surlan Popovic ${ }^{1}$ \\ ${ }^{1}$ Institute of Radiology, University Medical Centre Ljubljana, Ljubljana, Slovenia \\ 2 Department of Anaesthesiology and Surgical Intensive Care, Division of Surgery, University Medical Centre Ljubljana, \\ Ljubljana, Slovenia
}

Radiol Oncol 2020; 54(3): 253-262

Received 7 February 2020

Accepted 22 April 2020

Correspondence to: Assoc. Prof. Katarina Šurlan Popović, M.D., Ph.D., Clinical Institute of Radiology, University Medical Centre Ljubljana, Zaloška c 7, 1000 Ljubljana, Slovenia. E-mail: katarina.surlan-popovic@mf.uni-lj.si.

Disclosure: No potential conflicts of interest were disclosed.

Background. Severe bleeding after blunt maxillofacial trauma is a rare but life-threatening event. Non-responders to conventional treatment options with surgically inaccessible bleeding points can be treated by transarterial embolization (TAE) of the external carotid artery (ECA) or its branches. Case series on such embolizations are small; considering the relatively high incidence of maxillofacial trauma, the ECA TAE procedure has been hypothesized either underused or underreported. In addition, the literature on the ECA TAE using novel non-adhesive liquid embolization agents is remarkably scarce.

Patients and methods. PubMed review was performed to identify the ECA TAE literature in the context of blunt maxillofacial trauma. If available, the location of the ECA injury, the location of embolization, the chosen embolization agent, and efficacy and safety of the TAE were noted for each case. Survival prognostic factors were also reviewed. Additionally, we present an illustrative TAE case using a precipitating hydrophobic injectable liquid (PHIL) to safely and effectively control a massive bleeding originating bilaterally in the ECA territories.

Results and conclusions. Based on a review of 205 cases, the efficacy of TAE was $79.4-100 \%$, while the rate of major complications was about 2-4\%. Successful TAE haemostasis, Glasgow Coma Scale score $\geq 8$ at presentation, injury severity score $\leq 32$, shock index $\leq 1.1$ before TAE and $\leq 0.8$ after TAE were significantly correlated with higher survival rate. PHIL allowed for fast yet punctilious application, thus saving invaluable time in life-threatening situations while simultaneously diminishing the possibility of inadvertent injection into the ECA-internal carotid artery (ICA) anastomoses.

Key words: blunt maxillofacial trauma; external carotid artery injury; intractable bleeding; non-adhesive liquid embolization agent; precipitating hydrophobic injectable liquid, neurointervention

\section{Introduction}

Maxillofacial trauma comprises roughly $10 \%$ of all trauma cases. ${ }^{1}$ It is associated with a wide range of problems, including airway compromise, cervical spine injuries and bleeding. ${ }^{2}$ Life-threatening haemorrhage secondary to blunt maxillofacial trauma is considered rare, occurring in $1.2 \%-4.5 \%$ of trauma-related maxillofacial fracture cases..$^{2-5}$ The most common origins of haemorrhage in maxillofacial trauma are the internal maxillary artery (IMA), the IMA's distal branches, and the main trunk of the external carotid artery (ECA). ${ }^{6}$

A diverse range of imaging manifestations can present in the setting of blunt carotid artery trauma, including various dissection subtypes (mini- 


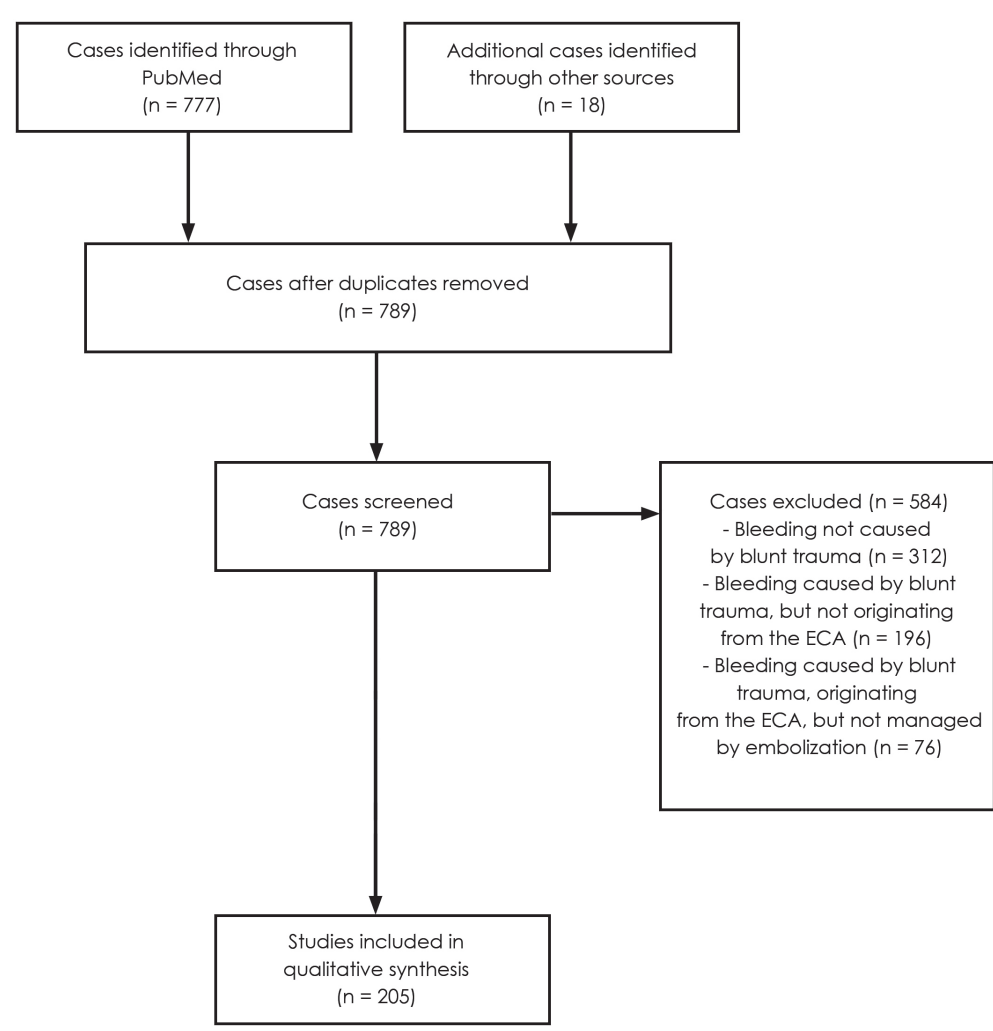

FIGURE 1. A flow diagram based on simplified Preferred Reporting Items for Systematic Reviews and MetaAnalyses (PRISMA) guidelines depicting the number of cases identified, included and excluded. The reasons for the exclusions are also noted. ${ }^{13}$ local bleeding points, the ability to perform superselective therapeutic vessel occlusion by cannulating the smaller vessel branches not amenable to open surgical repair, and short procedure time..$^{10} \mathrm{In}$ addition, ECA ligation oftentimes requires repeat ligation or subsequent TAE to effectively stop the bleeding, whereas TAE is usually efficacious in a single session. ${ }^{2,11}$ Furthermore, TAE offers the option to embolize the bleeding origins of a possible concomitant abdominal or other internal haemorrhage in the same session. ${ }^{12}$ In certain guidelines, surgical ECA ligation has been completely replaced by TAE for maxillofacial bleeding control. ${ }^{2}$

The initial search data for the review part of this manuscript was processed following a simplified variant of the Preferred Reporting Items for Systematic Reviews and MetaAnalyses (PRISMA) guidelines showing the number of cases identified, included and excluded, plus the reasons for exclusions (Figure 1). ${ }^{13}$ The included cases were then analysed in order to obtain the data regarding the use of embolization agents, and the efficacy and safety of the TAE procedure in the context of blunt maxillofacial trauma with bleeding originating from the ECA.

\section{Transarterial embolization of the ECA}

Embolization therapy aims at controlling an active bleeding by occluding the feeding artery with an embolization agent (EA). ${ }^{14}$ The TAE technique was first suggested by Brooks et al. in the 1930s. In the early 1970s, Rosch and Dotter used it for the first time to treat a traumatic vascular injury. ${ }^{15}$ It also became an accepted treatment option for a variety of vascular lesions unrelated to trauma, including arteriovenous malformations, glomus tumours, juvenile angiofibromas, and intracranial meningiomas. ${ }^{16} \mathrm{~A}$ pioneer case describing a successful IMA TAE in the treatment of intractable epistaxis was reported by Sokoloff et al. in $1974 .{ }^{17}$

Decades of innovation brought about major advances in embolization materials, however, to this day, the principles of the TAE procedure remain largely unaltered. ${ }^{18}$ Initially, a vascular access is established by a standard transfemoral approach using the Seldinger technique. ${ }^{19}$ Alternatively, brachial or axillary arterial access might be required in case of severe bilateral lower extremity injury. ${ }^{20}$ Diagnostic angiography of the whole circulation at risk is then performed, including bilateral common carotid arteries (CCAs), internal carotid arteries (ICAs), vertebral arteries (VAs), and ECAs. If the 
preliminary computed tomography angiography (CTA) or clinical findings suggest an injury to a specific smaller vessel, e.g. the IMA, the lingual artery or the superficial temporal artery, further microcatheter angiography of these territories is carried out. The purpose is to obtain a general overview of the complete vasculature and to exclude a possible concomitant injury to the CCA, ICA or VA. ${ }^{21}$ The vessel that is the source of an active haemorrhage is then therapeutically occluded. The aim of the embolization is to stop the active bleeding, prevent any subsequent rebleeding events, and preserve as much perfusion to the nearby structures as possible, thereby reducing the chance of unnecessary tissue damage. This means embolization is attempted as close to the lesion as possible to avoid occluding the vessels branching off proximally to the embolization site. Circumstances permitting, the culprit vessel should ideally be embolized both distally and proximally to the lesion in order to prevent rebleeding via the collateral circulation. ${ }^{21}$ The delivery of the EA is performed under fluoroscopic visualization to the point of contrast medium stasis within the embolized vessel.

\section{Embolization agents}

Depending on the vessel calibre, type of vessel injury and other factors, a variety of EAs with differing inherent properties and behaviour may be used. Historically, the first EA was autologous tissue (including blood clots, subcutaneous tissue and muscle) followed by silk threads. ${ }^{22}$ Their use gradually declined with the advances in newer EAs, imaging and (micro)catheter technologies. ${ }^{14,23}$

Data gathered in Table 1 indicates coils and gelatine foam (Gelfoam) are the EAs most frequently used for TAE in the context of blunt maxillofacial trauma. There have also been numerous instances of polyvinyl alcohol (PVA), microspheres, and N-butyl-2 cyanoacrylate (NBCA) use. One case of silastic spheres, two cases of Onyx, and a single case of precipitating hydrophobic injectable liquid (PHIL) use have been reported.

Coils are made from platinum or steel, measure $0.2-1.3 \mathrm{~mm}$ in diameter and can be supplied in a variety of lengths, shapes and levels of stiffness. They may be bare or fibered with materials such as wool, silk, nylon fibres, polyester, Dacron or PVA. ${ }^{18}$ Coils embolize a vessel by physically slowing down the local blood flow, by providing a thrombogenic locus, and by damaging the vessel wall, thus inducing the release of thrombogenic factors. Time to oc- clusion is typically 5 minutes or less after coil insertion, depending on the type of coil used, the rate of blood flow through the target vessel and the blood's coagulation properties. ${ }^{18}$ Larger diameter platinum coils offer good radiopacity, while smaller diameter coils (microcoils) provide for more targeted distal deployment. The possible complications of TAE using coils are non-target vessel occlusion, vessel injury, coil migration, and infection. ${ }^{18,24}$ Coils prohibit any future endovascular access distal to the occlusion point, which is particularly relevant in rebleeding events following collateralization. ${ }^{21}$

Gelatine foam (Gelfoam) (Pfizer, Kalamazoo, MI, USA) is a porous material with haemostatic properties prepared from purified porcine skin gelatine. It usually supplied as a block of sponge that needs to be cut into smaller cube- or torpedoshaped particles prior to embolization. Gelfoam induces foreign body reaction and necrotizing arteritis, resulting in the formation of a thrombus. ${ }^{25}$ Gelfoam as a standalone EA provides a temporary vessel occlusion; recanalization typically occurs within 3 weeks to 3 months, but the exact time and the extent cannot reliably be predicted. ${ }^{23} \mathrm{~A}$ combined coils-Gelfoam embolization may be particularly well suited for coagulopathic patients as such vessel occlusion is precise, fast, and permanent. ${ }^{23}$ The most significant disadvantage of Gelfoam-only embolization is the reliance on manual preparation of the particles, limiting the reproducibility and predictability of the exact embolization site. Furthermore, air bubbles typically form in the Gelfoam-contrast mixture, presenting a potential risk for an aerobic infection. ${ }^{18}$

Polyvinyl alcohol (PVA) particles (Boston Scientific, Cork, Ireland; Cordis J\&J Endovascular, Miami, FL, USA) are irregularly-shaped permanent embolic agents ranging from 100 to $1100 \mu \mathrm{m}$ in size. The PVA's mechanism of action includes adherence to the vessel wall, induction of an inflammatory reaction, focal angionecrosis and the resulting vessel fibrosis. There is a considerable variability in particle size because fragments smaller than the stated size range are allowed to enter the particulate mixture during production. This in turn increases the risk of distal, non-target embolization as particles tend to lodge in the smallest vessel they can fit in. On the other hand, the PVA particles are also prone to aggregation; this can lead to more proximal vessel occlusion than expected based on the stated size range of the particles. ${ }^{18}$

Microspheres (Embosphere and EmboGold, Merit Medical Systems, South Jordan, UT, USA; Contour SE, Boston Scientific, Natick, MA, USA; 
TABLE 1. Data from studies, case series and case reports pertaining to TAE of the ECA or its branches in the treatment of haemorrhage caused by blunt maxillofacial trauma

\begin{tabular}{|c|c|c|c|c|c|c|c|}
\hline First author & $\begin{array}{l}\text { Year } \\
\text { Pub- } \\
\text { lished }\end{array}$ & $\begin{array}{l}\text { Case } \\
\text { number }\end{array}$ & Vessel injured & Vessel embolized & $\begin{array}{l}\text { Emboli- } \\
\text { zation } \\
\text { agents } \\
\text { used }\end{array}$ & $\begin{array}{l}\text { efficacy (complete } \\
\text { cessation of bleeding } \\
\text { following TAE of the ECA } \\
\text { or its branches) }\end{array}$ & complications \\
\hline \multirow{7}{*}{ Bynoe $^{2}$} & \multirow{7}{*}{2003} & 1 & none identified & RL ECA & \multirow{7}{*}{$\begin{array}{l}\text { C } \\
\text { GF } \\
\text { PVA }\end{array}$} & \multirow{7}{*}{$100 \%$} & $\begin{array}{l}\text { partial tongue } \\
\text { necrosis }\end{array}$ \\
\hline & & 2 & R IMA & R IMA & & & none \\
\hline & & 3 & RIMA & RL IMA & & & none \\
\hline & & 6 & none identified & RL ECA above LA & & & none \\
\hline & & 7 & LIMA & L IMA & & & none \\
\hline & & 8 & LIMA & LIMA & & & $\begin{array}{l}\text { groin } \\
\text { hematoma }\end{array}$ \\
\hline & & 9 & LIMA & $\begin{array}{l}\text { R ECA above LA, L } \\
\text { IMA }\end{array}$ & & & none \\
\hline \multirow{7}{*}{ Chen $^{12}$} & \multirow{7}{*}{2009} & 12 & R IMA & not specified & $\begin{array}{l}\mathrm{C} \\
\mathrm{GF}\end{array}$ & \multirow{7}{*}{$100 \%$} & none \\
\hline & & 13 & LIMA & not specified & GF & & $\begin{array}{l}\text { could not be } \\
\text { assessed }\end{array}$ \\
\hline & & 14 & R IMA & not specified & GF & & none \\
\hline & & 15 & LIMA & not specified & GF & & none \\
\hline & & 16 & RL IMA & not specified & GF & & $\begin{array}{l}\text { could not be } \\
\text { assessed }\end{array}$ \\
\hline & & 17 & LECA & not specified & $\begin{array}{l}C \\
G F\end{array}$ & & none \\
\hline & & 18 & LIMA & not specified & GF & & none \\
\hline Cogbill 48 & 2008 & $19-39$ & $\begin{array}{l}\text { not discernible } \\
\text { due to the } \\
\text { merging of blunt } \\
\text { and penetrating } \\
\text { trauma patients' } \\
\text { data }\end{array}$ & $\begin{array}{l}\text { not discernible due } \\
\text { to the merging } \\
\text { of blunt and } \\
\text { penetrating trauma } \\
\text { patients' data }\end{array}$ & $\begin{array}{l}\mathrm{C} \\
\mathrm{GF}\end{array}$ & $85 \%$ & none \\
\hline \multirow{6}{*}{ Komiyama $^{50}$} & \multirow{6}{*}{1998} & 44 & not specified & $\begin{array}{l}\text { RL SPA, LPA, ADTA } \\
\text { IAA } \\
\text { A }^{7}, \text { FA, LA }\end{array}$ & \multirow{6}{*}{$\begin{array}{l}\text { C } \\
\text { GF } \\
\text { PVA }\end{array}$} & \multirow{6}{*}{$100 \%$} & none \\
\hline & & 45 & not specified & RL SPA, FA & & & none \\
\hline & & 46 & not specified & $\mathrm{BL} S \mathrm{SPA}, \mathrm{AAA}^{8}$ & & & $\begin{array}{l}\text { could not be } \\
\text { assessed }\end{array}$ \\
\hline & & 47 & not specified & R STA, FA & & & none \\
\hline & & 48 & not specified & RL GPA? EA & & & none \\
\hline & & 49 & not specified & RL SPA, SPAA ${ }^{10}$ & & & none \\
\hline \multirow{8}{*}{$\mathrm{Kuan}^{47}$} & \multirow{8}{*}{2015} & \multirow{8}{*}{$50-76$} & $12 \times I M A$ & & \multirow{8}{*}{$\begin{array}{l}\text { C } \\
\text { GF } \\
\text { PVA } \\
\text { NBCA }\end{array}$} & \multirow{8}{*}{$\begin{array}{l}92.3 \% \text {; data includes } \\
\text { one penetrating injury }\end{array}$} & \multirow{8}{*}{$\begin{array}{l}\text { no serious } \\
\text { systemic or } \\
\text { neurologic } \\
\text { complications }\end{array}$} \\
\hline & & & $6 \times \mathrm{FA}$ & & & & \\
\hline & & & $6 \times L A$ & & & & \\
\hline & & & $5 \times M_{M A}{ }^{11}$ & & & & \\
\hline & & & $3 \times \mathrm{ECA}$ & not specified & & & \\
\hline & & & $1 \times \mathrm{APA}^{12}$ & & & & \\
\hline & & & $5 x$ other vessels & & & & \\
\hline & & & $\begin{array}{l}\text { Note: this statistics } \\
\text { also includes } \\
\text { one penetrating } \\
\text { trauma. }\end{array}$ & & & & \\
\hline
\end{tabular}




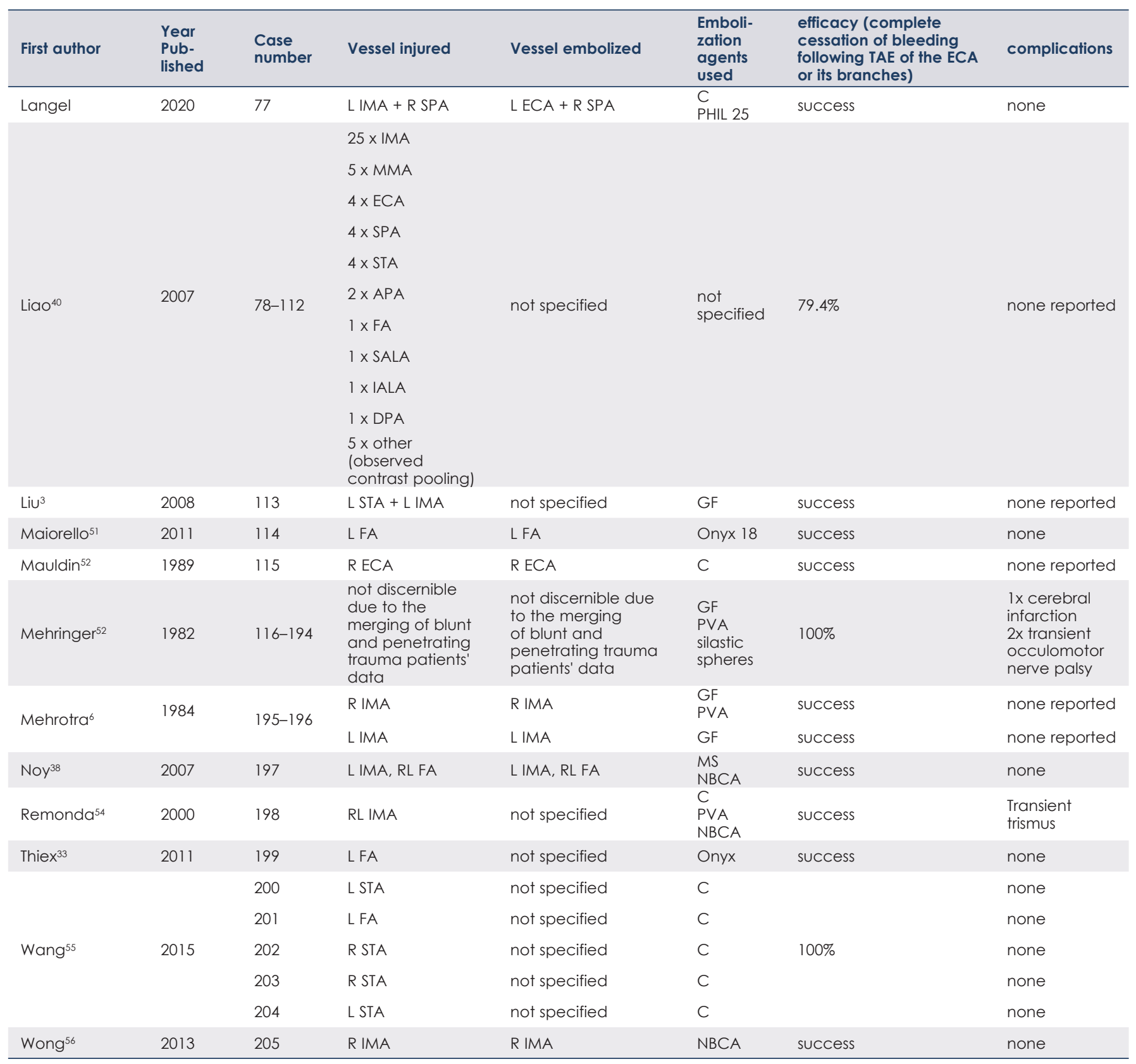

Anatomical abbreviations: $\mathrm{AAA}=$ anterior auricular artery; $\mathrm{ADTA}=$ anterior deep temporal artery; $\mathrm{APA}=$ ascending pharyngeal artery; DPA = descending palatine artery; $\mathrm{ECA}$ $=$ external carotid artery; $F A=$ facial artery; GPA = greater palatine artery; IAA = inferior alveolar artery; IALA = inferior alveolar artery; IMA = internal maxillary artery; IOA = infraorbital artery; $L=$ left; $L P A=$ lesser palatine artery; MMA = middle meningeal artery; $R=$ right; SALA = superior alveolar artery; $S P A=$ sphenopalatine artery; SPAA = superior posterior alveolar artery; STA = superficial temporal artery

Embolization agent abbreviations: C = coils; GF = Gelfoam; MS = microspheres; PHIL = precipitating hydrophobic injectable liquid; PVA = polyvinyl alcohol particles

Embozene, Celenova, San Antonio, TX, USA; Quadrasphere, Merit Medical Systems, South Jordan, UT, USA; Bead Block and LC Bead, Biocompatibles, Farnham, UK) are smooth globular structures made from an acrylic polymer matrix impregnated with porcine gelatine. They are hydrophilic, non-resorbable, non-aggregating, nonfragmenting spheres sized $40-1200 \mu \mathrm{m}$. Sizing inside a particular stated size range follows the Gaussian distribution and is thus more predictable 
than is the case with PVA particles. After lodging in vessels, microspheres induce a histological reaction similar to PVA particles. The most notable downside of using microspheres is the necessity to intermittently agitate the particle-saline suspension prior to application in order to prevent sedimentation. ${ }^{8,25,26}$ Also of note is the fact that microspheres of different manufacturers vary in elasticity and, as a consequence, particles of identical size range but different composition occlude vessels at different levels of the vascular tree. ${ }^{25,27}$

NBCA (TruFill, Cordis, Miami Lakes, FL; Histoacryl, B. Braun Aesculap, Tokyo, Japan; Glubran 2, Gem, Viareggio, Lucca, Italy) is a synthetic adhesive liquid EA (glue) that is accompanied by a separately packed tantalum powder, acting as a radiographic opacifier, and ethiodized oil, functioning as a polimerization retardant. All three components are mixed just before deployment. Once the solution is exposed to anionic environment such as blood, polymerization takes place at a rate dependent on the NBCA concentration. NBCA forms a permanent cast obstructing the vessel lumen. This occurs independently of the endogenous coagulation system - an important characteristic when dealing with exsanguinating trauma cases. ${ }^{18}$ NBCA glue also induces vessel wall inflammation reaction resulting in fibrosis. The downside of NBCA use is that the catheter may become glued to the vessel wall if not pulled back quickly enough following glue injection. Glue polymerisation can also occur both distally or proximally to the intended occlusion location. NBCA deployment thus requires a skilled operator. ${ }^{28}$

Silastic spheres are the oldest non-absorbable particulate EA, introduced in 1964, and have since been replaced by more modern EAs. ${ }^{29}$

Onyx (Medtronic, Dublin, Ireland) is an ethylene vinyl alcohol (EVOH) copolymer-based nonadhesive liquid EA dissolved in dimethyl sulfoxide (DMSO) with added radiopaque tantalum powder. It was introduced in 1990. As is the case with other DMSO-based non-adhesive liquid EAs, once injected, the DMSO component dissolves into the blood and the copolymer component starts gradually precipitating in a centripetal fashion. The non-adhesive nature allows for long injection times and mid-injection control angiography, if needed. Onyx's final solidification occurs in 5 minutes. ${ }^{30}$ There are several drawbacks to this EA, including long pre-injection preparation time (20 minutes of mixer shaking are required to achieve homogenization), a self-hiding effect when used in larger amounts due to high radiopacity, plenty of artefacts in a postinterventional imaging, and the potential to combust or produce sparks during monopolar surgical cauterization. ${ }^{31,32}$ In addition, Onyx's dark colour may result in a black discoloration of the skin after superficial embolization or subcutaneous extravasation of the EA.33,34

Precipitating hydrophobic injectable liquid (PHIL) (MicroVention, Tustin, CA, USA) is a nonEVOH copolymer-based non-adhesive liquid EA suspended in DMSO with iodine covalently bonded to copolymer to provide radiopacity. It was introduced in 2015. In comparison to Onyx, PHIL is supplied ready-to-use (no shaking is necessary), requires lower volume to achieve the same extent of embolization, is faster to fully precipitate ( $3 \mathrm{~min}$ utes), does not suffer from the self-hiding effect, produces fewer artefacts in postinterventional imaging, is not hazardous to surgical cauterization, and is not dark coloured which diminishes the possibility of skin discoloration. ${ }^{35,36}$ PHIL is also more homogenous on fluoroscopy during prolonged injections, but less radiopaque than Onyx once injected. ${ }^{23}$

According to the literature, no cases of blunt trauma-related ECA-territory embolization using other modern non-adhesive liquid EAs, such as Squid (Emboflu, Gland, Switzerland), have so far been reported. In the future, other cutting-edge EAs, such as homogenous microparticles or biodegradable drug-bearing microspheres produced by droplet microfluidics technology, are expected to see regular clinical use. ${ }^{37}$

\section{Efficacy and safety}

Various studies and case reports have shown the ECA TAE to be a safe and efficacious method in maxillofacial blunt-trauma related haemorrhage control, although direct comparison of the reviewed literature is rendered difficult by the variations in reporting. Two studies authored by Noy et al. and by Hayes et al. investigating intractable maxillofacial bleeding of various aetiologies, including but not limited to trauma, enrolling 74 patients in total, found TAE to be efficacious in 89.1 - 90.0\% ${ }^{38,39}$ A study by Liao et al. focusing exclusively on trauma-related oronasal bleeding enrolling 34 patients discovered TAE to be efficacious in $79.4 \%{ }^{40}$ The data collected in Table 1 show that the efficacy of TAE ECA ranges from $79.4 \%$ to $100 \%$, with the largest series attaining the perfect success rate comprising 10 cases. These results are similar to the efficacy of non-trauma-related TAE procedures involving the ECA (80\%-97\%). ${ }^{41-43}$ 
The complications among the 205 cases reviewed in Table 1 include groin hematoma (2 cases), cerebral infarction (1 case), partial tongue necrosis (1 case), transient occulomotor nerve palsy ( 1 case), and transient trismus (1 case), indicating an overall complication rate of $3 \%$. However, there is high variability in reporting styles regarding the complications. For example, certain authors limited the reporting only to serious neurologic or systemic complications without further expounding on the exact criterion that delimited the serious complications from the minor ones. Furthermore, complications that could not be assessed might have occurred, e.g. due to patient dying or entering a vegetative state. In addition, it was not possible to determine the risk of publication bias or selective reporting. It is thus safe to assume the overall complication rate to be higher than directly indicated by Table 1 data. Duncan et al. found the rate of major complications (comprising cerebral vascular insult only) to be $2 \%$ but also reported a rate of minor complications (comprising headache, transient facial pain, paraesthesia, and local groin complications) of $25 \%$ in their series of 57 embolizations, of these 3 trauma-related. ${ }^{44}$ Cullen and Tami reviewed the literature of 264 cases of IMA embolizations for the treatment of posterior epistaxis and found the rate of major complications (hemiplegia, facial nerve paralysis, cheek necrosis, ICA intimal injury, catheter stuck in a vessel, myocardial infarction) to be $4 \%$, and the rate of minor complications (IMA spasm, hypotension, hematoma, groin bleed, oedema, trismus, paraesthesia, persistent pain, skin slough, palate ulceration, aspiration pneumonia, hepatitis) to be $10 \% .{ }^{45}$

The relatively low rate of major complications might be in part due to the rich collateral flow between the ipsilateral and contralateral ECA branches distal to the lingual artery that ensure adequate tissue perfusion in case of one-sided ECA embolization. ${ }^{46,2}$ Duncan et al. discovered that the complication rate tends to drop with the use of microcatheter techniques. They have also observed a decrease in complication rate in the more recent studies that could be ascribed to factors such as improvement in catheter and guidewire design and increased operator experience. ${ }^{44}$

\section{Survival prognostic factors}

Liao et al. examined a series of 34 cases of craniofacial trauma requiring TAE and discovered that there was a significant contribution of successful
TAE haemostasis to patient survival ( $p=0.001)$. Glasgow Coma Scale score (GCS) $\geq 8$ at presentation, injury severity score (ISS) $\leq 32$, and shock index (SI; heart rate divided by systolic blood pressure) $\leq 1.1$ before TAE and $\leq 0.8$ after TAE were also significantly correlated with the patients' higher survival rate $(p<0.05)$. The need to treat a secondary abdominal bleeding origin by laparotomy significantly decreased the rate of survival ( $p=0.023$ ). The patients' age, the need to perform craniotomy, the bilateral distribution of the bleeding vessels, and the number of the haemorrhaging vessels per patient were not correlated with the patient survival $(p>0.05) \cdot{ }^{40}$

Kuan et al. confirmed some of the findings by Liao et al. and further discovered that patients with initial haemoglobin level lower than $10 \mathrm{~g} / \mathrm{dL}$ and patients with brain midline shift observed by computed tomography (CT) had statistically higher odds ratios predicting mortality than their counterparts as estimated by univariate logistic regression. ${ }^{47}$

\section{An illustrative case report}

A 20-year-old, previously healthy male was brought to the emergency department in 2019 after an acci-

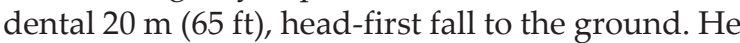
had been cleaning windows of his 7 th floor dorm room when he lost balance and fell. Eyewitnesses reported the patient had been lying on his stomach after impacting the ground but later managed to roll on his back by himself. A physician-led emergency medical service arrived on the scene in 10 minutes, finding the patient verbally responsive and making an effort to get up. Initial Glasgow Coma Scale (GCS) was an estimated 13. Severe facial trauma compromising the airway and, within a few minutes, cessation of spontaneous respiration necessitated rapid sequence intubation which proved challenging with several failed attempts. Asystole was observed on ECG prompting resuscitation efforts that resulted in the return of spontaneous circulation and sinus rhythm 20 minutes later. Upon arrival at a Level I trauma centre, the patient presented with GCS 5, blood pressure 70/40 $\mathrm{mmHg}$, heart rate $100 / \mathrm{min}$., a multifragment facial fracture (Figure 2A), a ruptured right eye, massive bleeding from the nose and the left ear, a fractured right 4th rib, a fractured left radius, a displaced left femoral fracture and a fractured left tibia. Adhering to our institution's standard trauma protocol, the possible abdominal and thoracic sources 


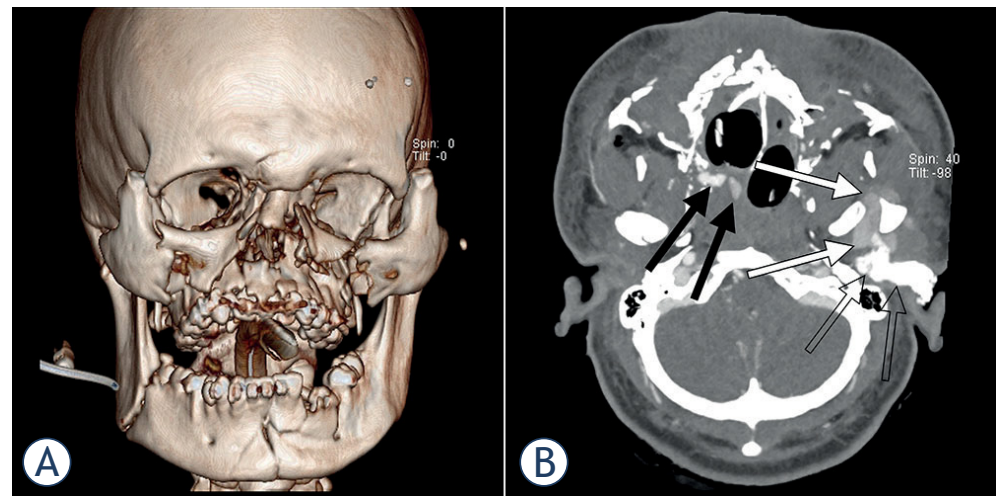

FIGURE 2. (A) A $3 D$ CT reconstruction showing multiple maxillo-facial fractures. (B) An aortocervical CTA showing two small hematomas in the region of the right pterygopalatine fossa and nasal cavity (black arrows) and a cm $3 \times 4 \mathrm{~cm}$ hematoma in the region of the left masticatory space and deep parotid space (white arrows). Also visible is a hyperdense material used in left ear tamponade (empty arrows)

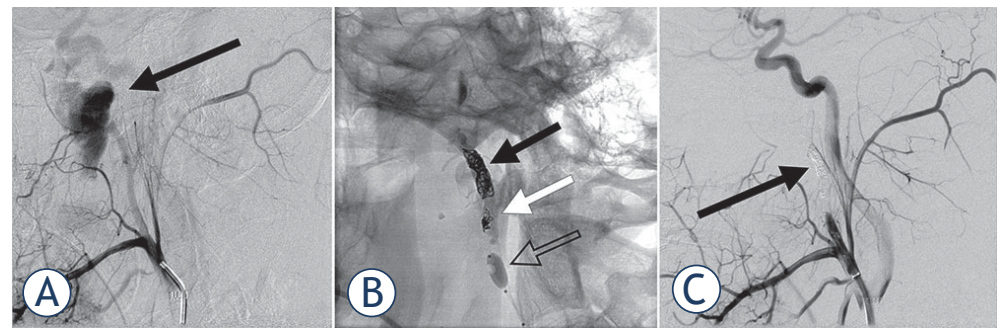

FIGURE 3. (A) A lateral left ECA angiogram showing ECA laceration with $3 \times 4$ $\mathrm{cm}$ pseudoaneurysm continuing into the proximal part of the left IMA. Contrast extravasation can be observed in the vicinity of the pseudoaneurysm. (B) A fluoroscopic view showing left ECA embolization using coils (black arrow) and PHIL 25 liquid embolization agent (white arrow) under balloon flow control (empty arrow). Also of note area small number of stray coils anchored in the vessel in the region of PHIL application (white arrow). (C) A post-embolization lateral left ECA angiogram showing complete exclusion of the ECA distally to the facial artery (black arrow).

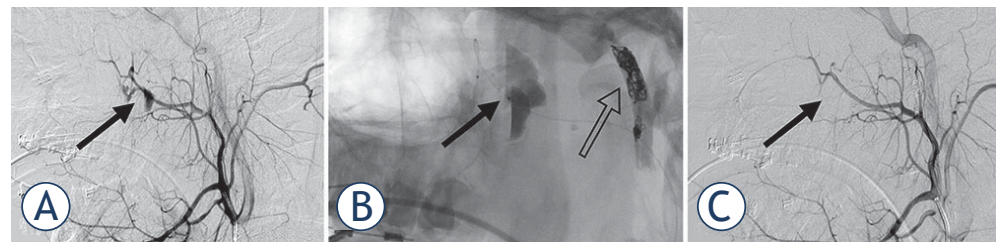

FIGURE 4. (A) A lateral right ECA angiogram showing two pseudoaneurysms in the region of the right pterygopalatine fossa and nasal cavity (black arrows). (B) Fluoroscopy showing microcatether proximally to the hematoma in the right pterygopalatine fossa (black arrow) prior to PHIL 25 application. Also visible is the embolized contralateral ECA (empty arrow). (C) A post-embolization right ECA angiogram showing complete sphenopalatine artery occlusion (black arrow). Also visible are the patent vessels proximally to the embolization. of major blood loss were excluded. Astonishingly, US, XR, CT and CTA imaging indicated no significant damage to the neurocranium, parenchymal organs or major thoracic or abdominal vessels. Aorto-cervical CTA was then performed, revealing contrast extravasation from the left IMA and the right sphenopalatine artery (SPA) (Figure 2B). This was consistent with the clinical presentation of severe antero-posterior epistaxis and pulsatile bleeding from the left ear. Nasal packing using balloon catheter inserted through the nares into the nasopharynx was performed by an ear, nose and throat (ENT) specialist to successfully control the nose bleeding. Tamponade of the left ear, however, proved to be inadequate with profound bleeding still persisting. Surgical treatment to control the haemorrhage by ligating the left ECA was decided against due to lesion inaccessibility caused by extensive soft tissue damage and swelling. Blood pressure remained low $(60 / 40 \mathrm{mmHg})$ despite having hitherto administered a total of 5 litres of fluids, including blood transfusion. Tranexamic acid and vasopressors were also applied, to little avail. In these life-threatening circumstances, TAE of the bleeding origins was considered the only remaining option.

The patient was transferred to the neurointerventional suite and a standard right transfemoral vascular access was established. Digital substraction angiography (DSA) showed a laceration of the left ECA with an ensuing $3 \times 4 \mathrm{~cm}$ pseudoaneurysm continuing into the proximal part of the left IMA (Figure 3A). DSA also showed a right SPA laceration with two small accompanying pseudoaneurysms (Figure 4A). The two culprit arteries were then superselectively catheterized and embolized. ECA embolization was performed using platinum coils and PHIL 25, while the SPA was embolized with PHIL 25 only (Figures 3B and 4B). In the case of the ECA embolization, coils created a mesh scaffold acting as a thrombogenic locus, and PHIL was then added to form a coagulopathy-independent lumen-obliterating cast. PHIL was chosen over other available liquid EAs for its ready-to-use characteristics, saving precious time in an emergency setting. In addition, its lava-like polymerisation properties ensured a well-controlled application, helping prevent any inadvertent injection into the dangerous ECA-internal carotid artery and ECAvertebral artery anastomoses.

Effort was made to embolize at or just proximal to the laceration point in order to preserve proximal arterial territories. Embolization was continued to the point of arterial stasis. Due to the well- 
developed left ECA and the resulting high blood flow to the pseudoaneurysm, the ECA embolization was performed under flow control provided by temporary proximal balloon occlusion. No flow control was needed for the SPA embolization. The embolizations of both lesions were immediately followed by complete cessation of the ear bleeding.

Postembolization imaging showed total exclusion of the lacerated vessels (Figures 3C and 4C), complete patency of all proximal vessels, no collateral pathways to the pseudoaneurysm and no other origins of bleeding. There were no procedurerelated complications.

To our knowledge, this case is the very first published report of PHIL 25 use for a safe and efficacious management of a massive bleeding originating in the ECA territory. Informed consent was obtained from the patient included in this case report as well as the consent for publication of the individual person's data.

\section{Conclusions}

Severe bleeding secondary to blunt maxillofacial trauma is a rare but life-threatening occurrence. Conventional treatment options include manual compression, nasal packing, coagulopathy correction, cauterization, fracture reduction and local vascular control. Open surgical ligation or TAE of the ECA are available as the most definite approaches. Both are similarly efficacious and safe, but TAE offers many advantages, including shorter procedure time, more precise haemorrhage localization, vessel occlusion superselectivity, and the ability to embolize a possible concomitant abdominal or other bleeding during the same session. Major complications of TAE are rare owing to rich collateral blood supply in the ECA territory, with the exception of the lingual artery. The diversion of embolization material into the ICA territories via the ECA-ICA anastomoses is a potentially hazardous complication warranting thorough preembolization angiographic overview of the whole vasculature at risk. There are several known factors positively affecting the survival of the maxillofacial trauma patients undergoing ECA TAE, most notably a successful TAE haemostasis, higher GCS, lower ISS, lower SI and higher haemoglobin level on arrival.

Novel non-adhesive liquid EAs such as PHIL allow for faster, more punctilious and coagulopathyindependent application, thus saving invaluable time in life-threatening situations while simultane- ously diminishing the possibility of inadvertent injection into the ECA-ICA anastomoses. Prospective randomized clinical studies comparing EAs are warranted to further evaluate their efficacy, safety and feasibility.

\section{References}

1. American College of Surgeons, Committee on Trauma. Advanced trauma life support manual. Chicago: American College of Surgeons; 1994.

2. Bynoe RP, Kerwin AJ, Parker HH 3rd, Nottingham JM, Bell RM, Yost MJ, et al. Maxillofacial injuries and life-threatening hemorrhage: treatment with transcatheter arterial embolization. J Trauma 2003; 55: 74-79. doi: 10.1097/01. TA.0000026494.22774.A0

3. Liu WH, Chen YH, Hsieh CT, Lin EY, Chung TT, Ju DT. Transarterial embolization in the management of life-threatening hemorrhage after maxillofacial trauma: a case report and review of literature. Am J Emerg Med 2008; 26: 516. e3-5. doi: 10.1016/j.ajem.2007.07.036

4. Thaller SR, Beal SL. Maxillofacial trauma: a potentially fatal injury. Ann Plast Surg 1991; 27: 281-3. doi: 10.1097/00000637-199109000-00015

5. Buchanan RT, Holtmann B. Severe epistaxis in facial fractures. Plast Reconstr Surg 1983 71: 768-71. doi: 10.1097/00006534-198306000-00003

6. Mehrotra ON, Brown GE, Widdowson WP, Wilson JP. Arteriography and selective embolisation in the control of life-threatening haemorrhage following facial fractures. Br J Plast Surg 1984; 37: 482-5. doi: 10.1016/00071226(84)90135-8

7. Sliker CW. Blunt cerebrovascular injuries: imaging with multidetector $\mathrm{CT}$ angiography. RadioGraphics 2008; 28: 1689-708. doi: 10.1148/rg.286085521

8. Biffl WL, Moore EE, Offner PJ, Brega KE, Franciose RJ, Burch JM. Blunt carotid arterial injuries: implications of a new grading scale. J Trauma 1999; 47: 84553. doi: 10.1097/00005373-199911000-00004

9. Ardekian L, Samet N, Shoshani $\mathrm{Y}$, Taicher S. Life-threatening bleeding following maxillofacial trauma. J Craniomaxillofac Surg 1993; 21: 336-8. doi: 10.1016/s1010-5182(05)80493-7

10. Radvany MG, Gailloud P. Endovascular management of neurovascular arterial injuries in the face and neck. Semin Intervent Radiol 2010; 27: 44-54. doi: 10.1055/s-0030-1247888

11. Mahmood S, Lowe T. Management of epistaxis in the oral and maxillofacial surgery setting: an update on current practice. Oral Surg Oral Med Oral Pathol Oral Radiol Endod 2003; 95: 23-9. 10.1067/moe.2003.10

12. Chen YF, Tzeng IH, Li YH, Lo YC, Lin WC, Chiang HJ, et al. Transcatheter arterial embolization in the treatment of maxillofacial trauma induced life-threatening hemorrhages. J Trauma 2009; 66: 1425-30. doi: 10.1097/ TA.0b013e3181842046

13. Moher D, Liberati A, Tetzlaff J, Altman DG; PRISMA Group. Preferred reporting items for systematic reviews and meta-analyses: the PRISMA statement. PLoS Med 2009; 6: e1000097. doi: 10.1371/journal.pmed.1000097

14. Hayes SB, Johnson JN, Most Z, Elhammady MS, Yavagal D, Aziz-Sultan MA. Transarterial embolization of intractable nasal and oropharyngeal hemorrhage using liquid embolic agents. J Neurointerv Surg 2015; 7: 537-41. doi: 10.1136/neurintsurg-2014-011101

15. Rosch J, Dotter C T, Brown M J. Selective arterial embolization: a new method for control of acute gastrointestinal bleeding. Radiology 1972; 102: 303-6. doi: 10.1148/102.2.303

16. Brooks B. The treatment of traumatic arteriovenous fistula. Med J 1930; 23: 100-6.

17. Sokoloff J, Wickbom I, McDonald D, Brahme F, Goergen TC, Goldberger LE. Therapeutic percutaneous embolization in intractable epistaxis. Radiology 1974; 111: 285-7. doi: 10.1148/111.2.285

18. Vaidya S, Tozer KR, Chen J. An overview of embolic agents. Semin Intervent Radiol 2008; 25: 204-15. doi: 10.1055/s-0028-1085930 
19. Seldinger SI. Catheter replacement of the needle in percutaneous arteriography; a new technique. Acta Radiol 1953; 39: 368-76. doi: 10.3109/00016925309136722

20. Bauer JR, Ray CE. Transcatheter arterial embolization in the trauma patient: a review. Semin Intervent Radiol 2004; 21: 11-22. doi: 10.1055/s-2004831401

21. Mangla S, Sclafani SJ. External carotid arterial injury. Injury 2008; 39: 1249 56. doi: 10.1016/j.injury.2008.06.012

22. Kunstlinger $F$, Brunelle $F$, Chaumont $P$, Doyon D. Vascular occlusive agents AJR Am J Roentgenol 1981; 136: 151-6. doi: 10.2214/ajr.136.1.151

23. Lubarsky M, Ray CE, Funaki B. Embolization agents-which one should be used when? Part 1: large-vessel embolization. Semin Intervent Radiol 2009; 26: 352-7. doi: 10.1055/s-0029-1242206

24. Vrachliotis TG, Falagas ME. Infections after endovascular coil embolization. Endovasc Ther 2007; 14: 805-6. 10.1583/07-2219C.1

25. Sheth RA, Sabir S, Krishnamurthy S, Avery RK, Zhang YS, Khademhosseini A et al. Endovascular embolization by transcatheter delivery of particles: past, present, and future. J Funct Biomater 2017; 8: E12. doi: 10.3390/jfb8020012

26. Lewis AL, Adams C, Busby W, Jones SA, Wolfenden LC, Leppard SW, et al. Comparative in vitro evaluation of microspherical embolisation agents. $J$ Mater Sci Mater Med 2006; 17: 1193-204 doi: 10.1007/s10856-006-0592-x

27. Liang $\mathrm{B}$, Xiong $\mathrm{F}, \mathrm{Wu} \mathrm{H}$, Wang $\mathrm{Y}$, Dong $\mathrm{X}$, Cheng $\mathrm{S}$, et al. Effect of transcatheter intraarterial therapies on the distribution of Doxorubicin in live cancer in a rabbit model. PLoS One 2013; 8: e76388. doi: 10.1371/journal. pone. 0076388

28. Niimi Y, Berenstein A, Setton A. Complications and their management during NBCA embolization of craniospinal lesions. Interv Neuroradiol 2003; 9: 157-64. doi: 10.1177/15910199030090\$122

29. Berenstein A, Lasjaunias P, Brugge KG. Surgical neuroangiography. Vol. 2: Clinical and endovascular treatment aspects in adults. Berlin: SpringerVerlag; 2004

30. Vollherbst DF, Sommer CM, Ulfert C, Pfaff J, Bendszus M, Mohlenbruch MA Liquid embolic agents for endovascular embolization: evaluation of an established (Onyx) and a novel (PHIL) embolic agent in an in vitro AVM model. Am J Neuroradiol 2017; 38: 1377-82. doi: 10.3174/ajnr.A5203

31. Siekmann R. Basics and principles in the application of Onyx LD Liquid Embolic System in the endovascular treatment of cerebral arteriovenous malformations. Interv Neuroradiol 2005; 11: 131-40. doi: $10.1177 / 15910199050110 \$ 117$

32. Schirmer CM, Zerris V, Malek AM. Electrocautery-induced ignition of spark showers and self-sustained combustion of onyx ethylene-vinyl alcohol copolymer. Neurosurgery 2006; 59: ONS413-8. doi: 10.1227/01. NEU.0000240683.15391.99

33. Thiex R, Wu I, Mulliken JB, Greene AK, Rahbar R, Orbach DB, Safety and clinical efficacy of Onyx for embolization of extracranial head and neck vascula anomalies. AJNR Am J Neuroradiol 2011; 32: 1082-6. doi: 10.3174/ajnr A2439.

34. Koo HW, Lee JJ. Forehead pigmentation after Onyx embolization for dural arteriovenous fistula presenting with parkinsonism. Interdiscip Neurosurg 2020; 19: 100616. doi: 10.1016/j.inat.2019.100616

35. Leyon JJ, Chavda S, Thomas A, Lamin S. Preliminary experience with the liquid embolic material agent PHIL (Precipitating Hydrophobic Injectable Liquid) in treating cranial and spinal dural arteriovenous fistulas: technical note. J Neurointerv Surg 2016; 8: 596-602. doi: 10.1136/neurintsurg-2015-011684

36. Koçer N, Hanımoğlu H, Batur S, Kandemirli SG, Kızılkılıç O, Sanus Z Preliminary experience with precipitating hydrophobic injectable liquid in brain arteriovenous malformations. Diagn Interv Radiol 2016; 22: 184-9. doi: 10.5152/dir.2015.15283

37. Li W, Zhang L, Ge X, Xu B, Zhang W, Qu L, et al. Microfluidic fabrication of microparticles for biomedical applications. ChemSoc Rev 2018; 47: 5646-83. doi: $10.1039 / c 7 c s 00263$

38. Noy D, Rachmiel A, Emodi O, Amsalem Y, Israel Y, Nagler RM. Transarteria embolization in maxillofacial intractable potentially life-threatening hemorrhage. J Oral Maxillofac Surg 2017; 75: 1223-31. doi: 10.1016/j. joms.2017.01.033
39. Hayes SB, Johnson JN, Most Z, Elhammady MS, Yavagal D, Aziz-Sultan MA Transarterial embolization of intractable nasal and oropharyngeal hemorrhage using liquid embolic agents. J Neurointerv Surg 2015; 7: 537-41. doi: 10.1136/neurintsurg-2014-011101

40. Liao CC, Hsu YP, Chen CT, Tseng YY. Transarterial embolization for intractable oronasal hemorrhage associated with craniofacial trauma: evaluation of prognostic factors. J Trauma 2007; 63: 827-30. doi: 10.1097/ TA.0b013e31814b9466

41. Roberson $\mathrm{G}$, Rearden E. Angiography and embolization of the internal maxillary artery for posterior epistaxis. Arch Otolaryngo/1979; 105: 333-7. doi: 10.1001/archotol.1979.00790180031006

42. Vitek J. Idiopathic intractable epistaxis: endovascular therapy. Radiology. 1991; 181: 113-6. doi: 10.1148/radiology.181.1.1887018

43. Elahi M, Parnes LS, Fox AJ, Pelz DM, Lee DH. Therapeutic embolization in the treatment of intractable epistaxis. Arch Otolaryngol Head Neck Surg1995; 121: 65-9. doi: 10.1001/archotol.1995.01890010051009

44. Duncan IC, Fourie PA, le Grange CE, van der Walt HA. Endovascular treatment of intractable epistaxis - results of a 4-year local audit. S Afr Med J 2004; 94: 373-8. doi: 10.4102/sajr.v8i3.118

45. Cullen MM, Tami TA. Comparison of internal maxillary artery ligation versus embolization for refractory posterior epistaxis. Otolaryngol Head Neck Surg 1998; 118: 636-42. doi: 10.1177/019459989811800512

46. Burdick TR, Hoffer EK, Kooy T, Ghodke B, Starnes BW, Valji K, et al. Which arteries are expendable? The practice and pitfalls of embolization throughout the body. Semin Intervent Radiol 2008; 25:191-203. doi: 10.1055/s-00281085925.

47. Kuan CH, Lin CY, Hsaio JK, Chen JS, Han YY. Prognostic factors of survival from intractable oronasal bleeding after successful transarterial embolization. Oral Maxillofac Surg 2015; 73: 1790-4. doi: 10.1016/j.joms.2015.03.028

48. Cogbill TH, Cothren CC, Ahearn MK, Cullinane DC, Kaups KL, Scalea TM, et al. Management of maxillofacial injuries with severe oronasal hemorrhage: a multicenter perspective. J Trauma 2008; 65: 994-9. doi: 10.1097/ TA.0b013e318184ce12.

49. Kim DY, Dong DK, Park H, Chung J. Endovascular treatment of life-threatening bleeding of bilateral maxillary arteries in a patient with multiple facial bone fractures - a case report. J Korean Neutrotraumatol Soc 2011; 7: 108111. doi: $10.13004 / j k n t s .2011 .7 .2 .108$

50. Komiyama M, Nishikawa M, Kan M, Shigemoto T, Kaji A. Endovascular treatment of intractable oronasal bleeding associated with severe craniofacial injury. J Trauma 1998; 44: 330-4. doi: 10.1097/00005373-199802000-00017

51. Maioriello AV, Stanley DJ, Ho T, Ashley WW. Successful Onyx embolization of life threatening traumatic posterior jugal artery fistula following mandibular fracture. J Neurointerv Surg 2012; 4: e15. doi: 10.1136/neurintsurg-2011-010071

52. Mauldin FW, Cornay WJ 3rd, Mahaley MS Jr, Hicks JN. Severe epistaxis from a false aneurysm of the external carotid artery. Otolaryngol Head Neck Surg 1989; 101: 588-90. doi: 10.1177/019459988910100515

53. Mehringer CM, Hieshima GB, Grinnell VS, Tsai FY, Bentson JR, Hasso AN, et al. Therapeutic embolization for vascular trauma of the head and neck. AJNR Am J Neuroradiol 1983; 4: 137-42. PMID: 6405591

54. Remonda L, Schroth G, Caversaccio M, Lädrach K, Lövblad KO, Zbären $P$, et al. Endovascular treatment of acute and subacute hemorrhage in the head and neck. Arch Otolaryngol Head Neck Surg 2000; 126: 1255-62. doi: 10.1001/archotol.126.10.1255

55. Wang D, Su L, Han Y, Fan X. Embolization treatment of pseudoaneurysms originating from the external carotid artery. J Vasc Surg 2015; 61: 920-6. doi: 10.1016/j.jvs.2014.10.093

56. Wong CW, Tan WC, Yeh YT, Chou MC, Yeh CB. Transarterial embolization for traumatic intractable oronasal hemorrhage. J Emerg Med 2013; 44: 108891. doi: 10.1016/j.jemermed.2012.06.029 